\title{
Sensitivity of the North Atlantic to Surface Forcing in an Ocean General Circullation Model
}

\author{
Martin R. WADley and Grant R. BigG \\ School of Environmental Sciences, University of East Anglia, Norwich, United Kingdom \\ David P. STeVens and John A. Johnson \\ School of Mathematics, University of East Anglia, Norwich, United Kingdom
}

(Manuscript received 5 January 1995, in final form 17 July 1995)

\begin{abstract}
The sensitivity of the circulation and surface properties of the North Atlantic to different forms of surface forcing is investigated using a Bryan and Cox type model. Forcing taking the form of heat and freshwater fluxes calculated using bulk aerodynamic formulae (with an effective salt flux representing freshwater forcing) failed to simulate the low salinity region in the Labrador Sea and north of the Gulf Stream. By contrast, the use of this form of surface forcing, but with direct freshwater forcing and transport instead of the more commonly used salt flux, reproduces the low salinity in these regions and gives a circulation in good agreement with that obtained using the robust diagnostic mode. Since coupled climate models currently use an artificial salt flux form for the freshwater fluxes between ocean and atmosphere, the poor performance of this surface forcing reported here has significant implications for climate prediction.
\end{abstract}

\section{Introduction}

Two distinct types of simulation of the ocean circulation using ocean general circulation models (OGCMs) are currently carried out. The first type takes models run in the robust diagnostic mode (Sarmiento and Bryan 1982), with relaxation to climatology at all depths. These attempt to diagnose, and hence understand, the circulation from known temperature, salinity, and wind fields. Robust diagnostic simulations assume that the modeled circulation must be constrained to resemble the real circulation. Such simulations only take a few years to spin up, allowing high resolutions to be used. To allow significant freedom in simulations purely designed to understand contemporary ocean climate (rather than its evolution) it is then common to remove the internal relaxation and use only surface relaxation to drive the model. This is partly due to the limited amount of subsurface, and particularly deep, data to constrain the model, but also to produce a simulation in which the surface relaxation effectively parameterizes the fluxes of heat and fresh water (diagnosed as a salt flux because of the relaxation of the surface salinity) across the air-sea interface. Two recent examples of such simulations are described by

Corresponding author address: Dr. Martin R. Wadley, School of Environmental Sciences. University of East Anglia, Norwich NR4 7TJ, U.K.
Semtner and Chervin (1992) and The FRAM Group (1991).

The second type of simulation is concerned with longer-term variability in the circulation and may involve coupling with an atmospheric general circulation model. These simulations require hundreds to thousands of years and consequently use a rather coarser resolution. Surface forcing determines the temperature and salinity at all depths and so must be physically realistic to achieve meaningful results. Some models of this type in ocean-only mode have used relaxation toward idealized surface properties to determine surface fluxes of heat and salt and then imposed the diagnosed salt flux to allow the salinity fields to evolve free from climatological restrictions (Bryan 1986). This leads, however, to oscillatory behavior (Marotzke et al. 1988; Weaver and Sarachik 1991; Moore and Reason 1993). Other coupled mode and ocean-only simulations have used bulk aerodynamic fluxes to parameterize the exchange of heat and salt between the ocean and atmosphere (Bigg et al. 1992; Bigg 1994) or, more simply for heat fluxes, relaxation to observed (or modeled) air temperatures (Haney 1974; Han 1988). In all of these simulations the supply of freshwater to the ocean surface is modeled as an effective salt flux rather than the real flux of fresh water. This commonly leads to a slight net imbalance in salinity (Bigg and Jiang 1993), which becomes significant over time (Weaver and Sarachik 1991) 


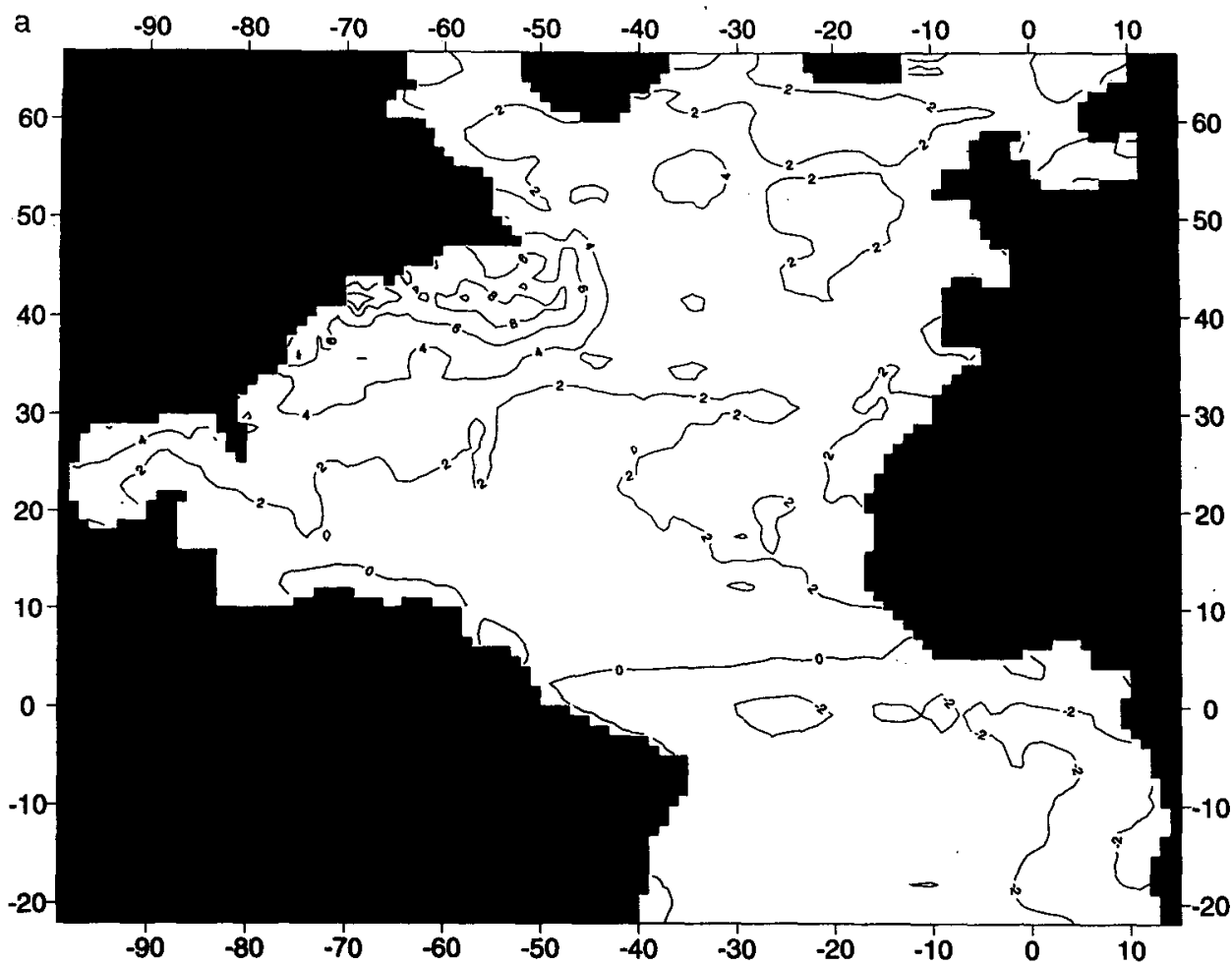

FIG. 1. Sea surface temperature difference between the model in January of year 11 and the robust diagnostic state (RD) for each of the experiments: (a) experiment A with surface relaxation, (b) experiment $B$ with physically based fluxes (applied as a salt flux), and (c) experiment $\mathbf{C}$ with physically based fluxes (applied as a freshwater flux). The contour interval is $2^{\circ} \mathrm{C}$.

Thus, until recently, the transport of freshwater within the ocean has been effectively ignored. The representation of freshwater transport by a salt flux, designed to maintain the observed surface salinity effectively moves salt in the opposite direction to the real freshwater transport. This forced salt flux could, if large enough, lead to modeled currents flowing in the opposite direction to reality. Huang (1993) pointed out that including freshwater transport gives a natural boundary condition, removing the need for artificial salt transport within the ocean and across the air-sea interface. His results show that including freshwater transport can significantly modify the predicted circulation, suggesting that the commonly used salt flux forcing is a poor parameterization of the exchange of water across the air-sea interface. This conclusion is especially troubling for current coupled climate models because of the inherent feedback between the atmosphere and a potentially inaccurate ocean surface.

In this paper we examine the response of a North Atlantic model to three different surface forcing methods, showing the considerable impact on the circulation of a real freshwater flux compared with two more usual surface forcing techniques. The results from an atmospheric climate simulation (Valdes, unpublished manuscript, but similar to Hoskins and Valdes 1990) are used to force the ocean. The atmospheric model is a version of that used by the U.K. Universities Global Atmospheric Modelling Programme (UGAMP), effectively with $128 \times 64$ points, and triangular truncation at total wavenumber 42 . The first experiment (A) uses the traditional relaxation to climatological surface temperature and salinity, whereas the second (B) uses the atmospheric simulation results to evaluate physically based heat and freshwater fluxes, but with the freshwater flux treated as a standard salt flux. In the third experiment $(\mathrm{C})$, freshwater transport replaces the effective salt flux of experiment (B) using the method of Huang (1993).

\section{Model details}

A Cox-type OGCM (Cox 1984), with a $1^{\circ}$ grid, 19 levels, and open boundaries (Stevens 1990) at $21^{\circ} \mathrm{S}$ and $67^{\circ} \mathrm{N}$, is used. Baroclinic exchange is permitted at the open boundaries, with the barotropic flow specified using the Sverdrup balance on the southern boundary, and results from an OGCM of the Norwegian-Greenland Sea (Stevens 1991) on the northern boundary where the Sverdrup balance is unsuitable. In the Labrador Sea a barotropic cyclonic circulation of $5 \mathrm{~Sv}\left(\mathrm{~Sv} \equiv 10^{6}\right.$ $\mathrm{m}^{3} \mathrm{~s}^{-1}$ ) is imposed at the northern boundary of the 

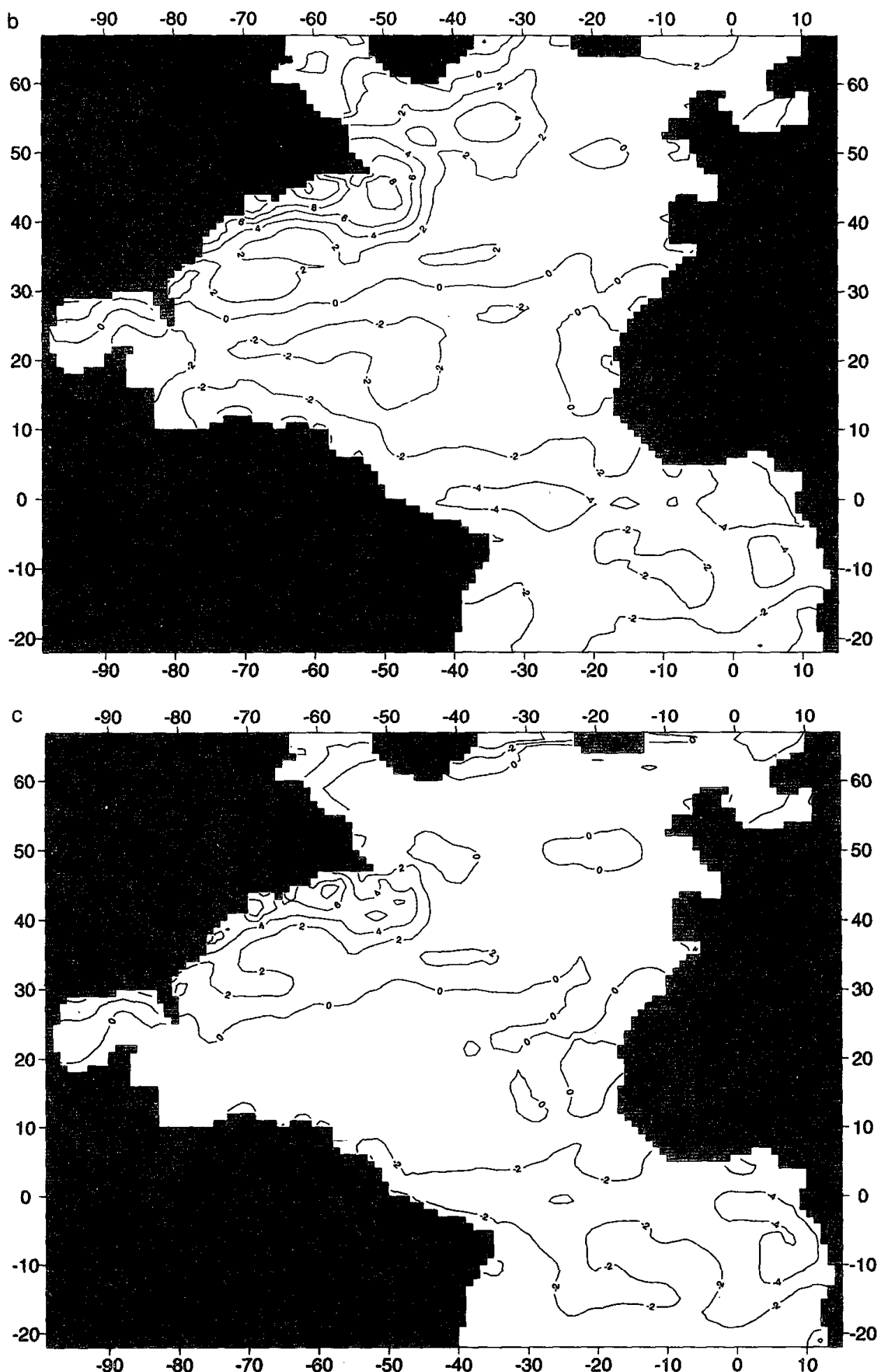

FIG. 1. (Continued) 
model ( to give no net flow across this part of the boundary), consistent with measurements by Lazier and Wright (1993). At outflow points on the boundary the temperature and salinity are extrapolated from the interior but, where flow is into the model domain, relaxation to the Levitus (1982) climatological data is used to ensure correct inflow properties. An open boundary is also used to permit exchange with the Mediterranean. This exchange is found to be too weak with a natural geostrophic balance, so the meridional surface temperature gradient across the Strait of Gibraltar is adjusted each time step to ensure that the thermal wind balance gives the observed exchange of $\sim 1$ Sv (Bryden 1990). Since the surface water is advecting into the Mediterranean (i.e., out of the model domain), the artificial alteration of the surface temperature does not affect the Atlantic. The deep water flowing from the Mediterranean to the Atlantic has properties from the Levitus (1982) climatology.

The experiments described in this paper are all initialized with the mean Levitus data for each level in the model and spun up for 3 years by relaxing toward the Levitus temperature and salinity data at all depths below the surface with a timescale of 3 months. During this period relaxation to the seasonal Levitus and Oort (1977) temperature and annual mean Levitus (1982) salinity is used at the surface to parameterize the fluxes of heat and salt. An additional salt flux is imposed at points adjacent to river outflows to parameterize the input of freshwater (see section 3 for more details). After 3 years of robust diagnostic integration the subsurface relaxation is removed, and each experiment imposes a different parameterization of the surface heat and salt/freshwater fluxes, as described in section 3.

The experiments use wind stresses from the seasonal atmospheric simulation of Valdes (unpublished manuscript), which is similar to Hoskins and Valdes (1990). The Denmark Strait sill lies at $67^{\circ} \mathrm{N}$, which is the same latitude as the model's northern boundary. The open boundary condition is unable to produce a realistic flux over the sill, so the sill was moved $5^{\circ} \mathrm{S}$ of the boundary to allow the correct formation of water masses in the region, with successful results.

\section{Surface forcing}

\section{a. Experiment A: Surface relaxation}

This method adjusts the surface temperature and salinity toward observed values over a suitable timescale using

$$
Q_{\text {heat }}=\frac{1}{\alpha_{1}}\left(T_{c}-T_{m}\right), \quad Q_{\text {salt }}=\frac{1}{\alpha_{2}}\left(S_{c}-S_{m}\right),
$$

where $Q_{\text {heat }}$ and $Q_{\text {salt }}$ are the surface fluxes of heat and salt; $T_{c}$ and $S_{c}$ are the climatological temperature and salinity; $T_{m}$ and $S_{m}$ are the model surface temperature and salinity; $\alpha_{1}=\alpha / c \rho H, \alpha_{2}=\alpha / H$, where $\alpha$ is the relaxation timescale (typically 30 days for seasonally varying forcing); $c$ is the specific heat capacity of sea water; $\rho$ is the density of sea water; and $H$ is the depth of the surface model level. This effectively produces air-sea heat and salt fluxes that are dependent on the differences between the observed values and those predicted by the model. This method, employed in experiment A, can produce realistic circulation fields (FRAM Group 1991; Semtner and Chervin 1992) but obviously cannot be used for studies in climate variability where the surface properties are not known a priori.

Mixed boundary conditions have also been used by, for example, Bryan (1986), Marotzke et al. (1988), Weaver and Sarachik (1991), Moore and Reason (1993), and Power et al. (1994), with relaxation used for the heat flux but a flux (diagnosed by relaxation) being used for the salt forcing. This method only constrains the temperature field, allowing major changes in circulation associated with different salinity distributions. However, such surface boundary conditions lead to instability and also do not conserve salt (Weaver and Sarachik 1991). We have therefore not included this formulation in our set of experiments.

\section{b. Experiment B: Physically parameterized fluxes but with a virtual salt flux}

A second method involves parameterizing the surface fluxes with physically based bulk aerodynamic flux formulas using atmospheric data as a boundary condition. Various partial adaptations of this are in the literature (Philander and Seigel 1985; McCreary and Kundu 1989), but the version used here is that of Bigg et al. (1992) and fully described in Bigg (1994). Heat fluxes are calculated using monthly average air-sea temperature and humidity gradients and the radiation balance. The surface temperature is thus predicted in a physically based way that retains partial thermal feedback with atmospheric climatology through the longwave and sensible heat fluxes, counteracting the longterm temperature drift associated with imposition of direct fluxes (Carrington and Anderson 1993).

Local freshwater fluxes $(P-E)$ are calculated, as an effective salt flux, from the difference between precipitation $P$, given by the atmospheric model, and evaporation $E$, calculated as part of the latent heat flux. Additional freshwater is supplied by river runoff. This is added into appropriate gridboxes adjacent to river mouths, again as an effective salt flux (that is, salt is extracted rather than freshwater being added in proportion to the real amount of dilution). The monthly average runoff from each catchment draining into the model domain is calculated by integrating the atmospheric model precipitation over each catchment and multiplying by a runoff coefficient, taken from observations (Atlas of World Water Balance 1974). This coefficient ranges from 0.9 for Norway to 0.05 for sub- 


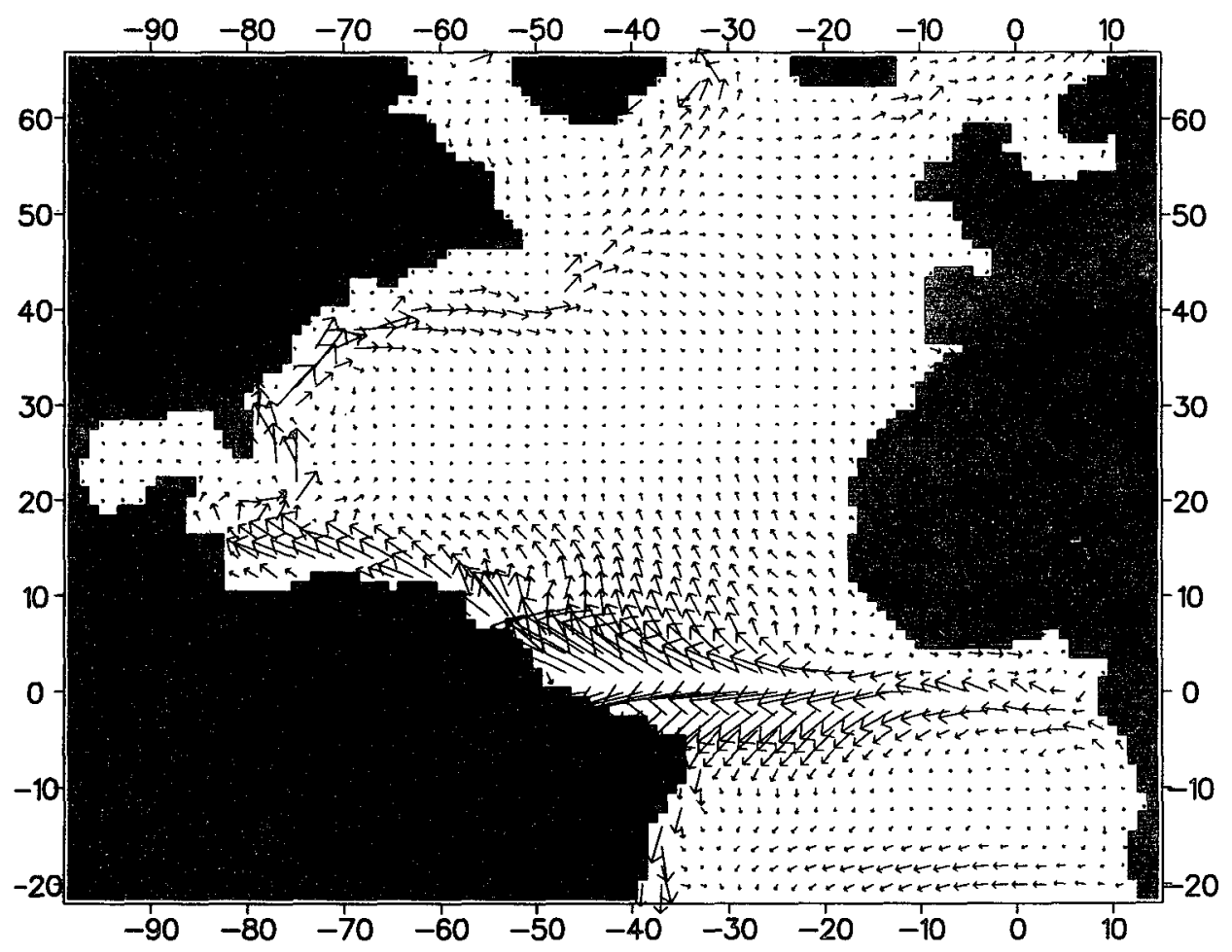

FIG. 2. Surface velocity for experiment A in January of year 11. An arrow length equal to the grid spacing represents a velocity of $10 \mathrm{~cm} \mathrm{~s}^{-1}$.

Saharan Africa. The catchments are either large scale and well known, such as drainage into the St. Lawrence system, or small scale and effectively only local drainage through coastal grid points, such as off Norway. The freshwater, or more correctly salt, flux is independent of surface salinity.

This method allows evolution of the oceanic temperature and salinity fields to be determined only by the atmospheric model variability and thus permits climate prediction. It also allows prediction of ice extent, which is essential for climate problems, where changes in circulation are linked to changes in ice cover (Saltzmann and Moritz 1980). Experiment B will thus allow adjustment to, and conservation of, the heat fluxes but it does not necessarily conserve salt (Bigg and Jiang 1993).

\section{c. Experiment C: Physically parameterized fluxes but with a freshwater flux}

In the real ocean only a very small amount of salt enters or leaves (mainly due to wave breaking and bubble bursting and longer-term geological cỳcling), so salt is essentially conserved. The heat flux parameterization of experiment $B$ allows feedback between ocean and atmosphere, conserving heat. However, the effective salt flux of experiment $B$ does not, in general, conserve salt, although the "correct" value of the amount of freshwater added or lost to each grid square is calculated. Huang (1993) developed a new surface freshwater flux and transport scheme, which, as in reality, adds freshwater to the model and so correctly conserves salt. In this formulation the barotropic flow is no longer only expressed in terms of a nondivergent streamfunction, but also by a potential function that represents the divergence introduced by the local freshwater balance. The historical variation of mean sea level suggests that the global ocean roughly conserves water over century timescales. However, a single ocean basin may export or import water from elsewhere to maintain this level. In experiment $C$ our model therefore needs to allow this export or import to occur, and this was permitted by allowing the appropriate water exchange at each time step to occur across the open southern boundary.

This third experiment $(C)$ thus combines the heat conservation of a bulk aerodynamic heat flux formulation with the freshwater and salt conservation devised by Huang (1993).

\section{Comparison of experiments}

The experiments using each of the three different types of surface forcings described above were run for 7 years from a common 3-year robust diagnostic (RD) spinup of the circulation fields. This RD state was assumed to represent the "best guess" of the circulation 


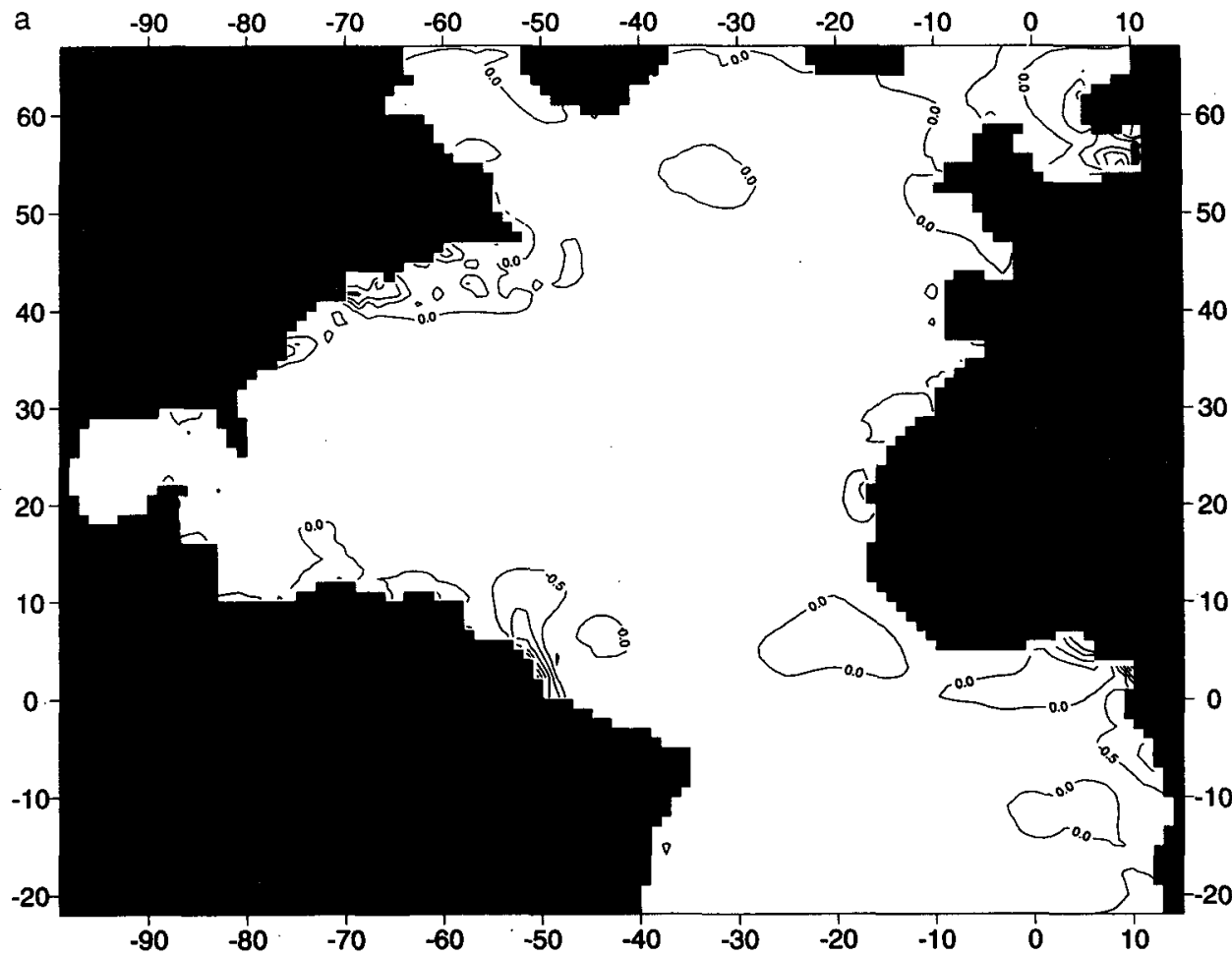

FIG. 3. Sea surface salinity difference between the model in January of year 11 and the robust diagnostic state (RD) for each of the experiments: (a) experiment A with surface relaxation, (b) experiment $B$ with physically based fluxes (applied as a șalt flux), and (c) experiment $\mathrm{C}$ with physically based fluxes (applied as a freshwater flux). The contour interval is 0.5 psu.

obtainable for this model from existing climatology and the atmospheric model fields used. Most of the discussion below deals with comparisons between this RD common initial state and the final, January, state of each experiment. Sensitivity to errors in the runoff or precipitation fields, for example, was not investigated because the purpose of this work was to show the firstorder differences resulting from each forcing technique, with as many fixed parameters between each experiment as possible. There may also be errors introduced by the use of monthly averages, rather than including the diurnal cycle, in the various forcing fields. However, again the intention of this work is not to explore these nonlinearities but only the clear circulation differences resulting from the formulation of the surface forcing.

\section{a. Surface temperature}

Comparison between the sea surface temperature (SST) of the RD state (essentially the Levitus climatology) and the three different experiments is shown in Fig. 1 for January of year 11. All experiments overestimate temperature along the east coast of the United States and underestimate temperatures in the tropical Atlantic. The first of these biases is due to the model's
Gulf Stream separating from the coastline too far north-a standard fault with OGCMs (e.g., Semtner and Chervin 1988). This bias can be seen in Fig. 2, which shows the surface velocity for experiment $A$ in January (on the scale shown the differences in velocities between the three experiments is slight so only one experiment is shown-see section $4 \mathrm{c}$ for a discussion of the significant, if visually slight, circulation differences). Separation occurs near Cape Cod, rather than Cape Hatteras, and the northward overshoot of the warm waters south of the Gulf Stream gives the large but localized temperature excesses. Note that the best simulation in this region is experiment $\mathrm{C}$ using the freshwater flux forcing. In this experiment, in contrast to both A and B, the northeast Atlantic SST is well estimated and the overestimate is restricted to the coastal zone. We will see in section 5 that the other two experiments, particularly experiment $B$, have an artificial component of northward advection in this region because of the use of an effective salt flux for the freshwater flux that adds to the temperature overestimate.

The underestimated SST in the Tropics is due to excessive equatorial and (Southern Hemisphere) coastal upwelling. This again is a common fault of OGCMs and is not limited to coarse-resolution simulations (Semtner and Chervin 1992). It is also partly due to 

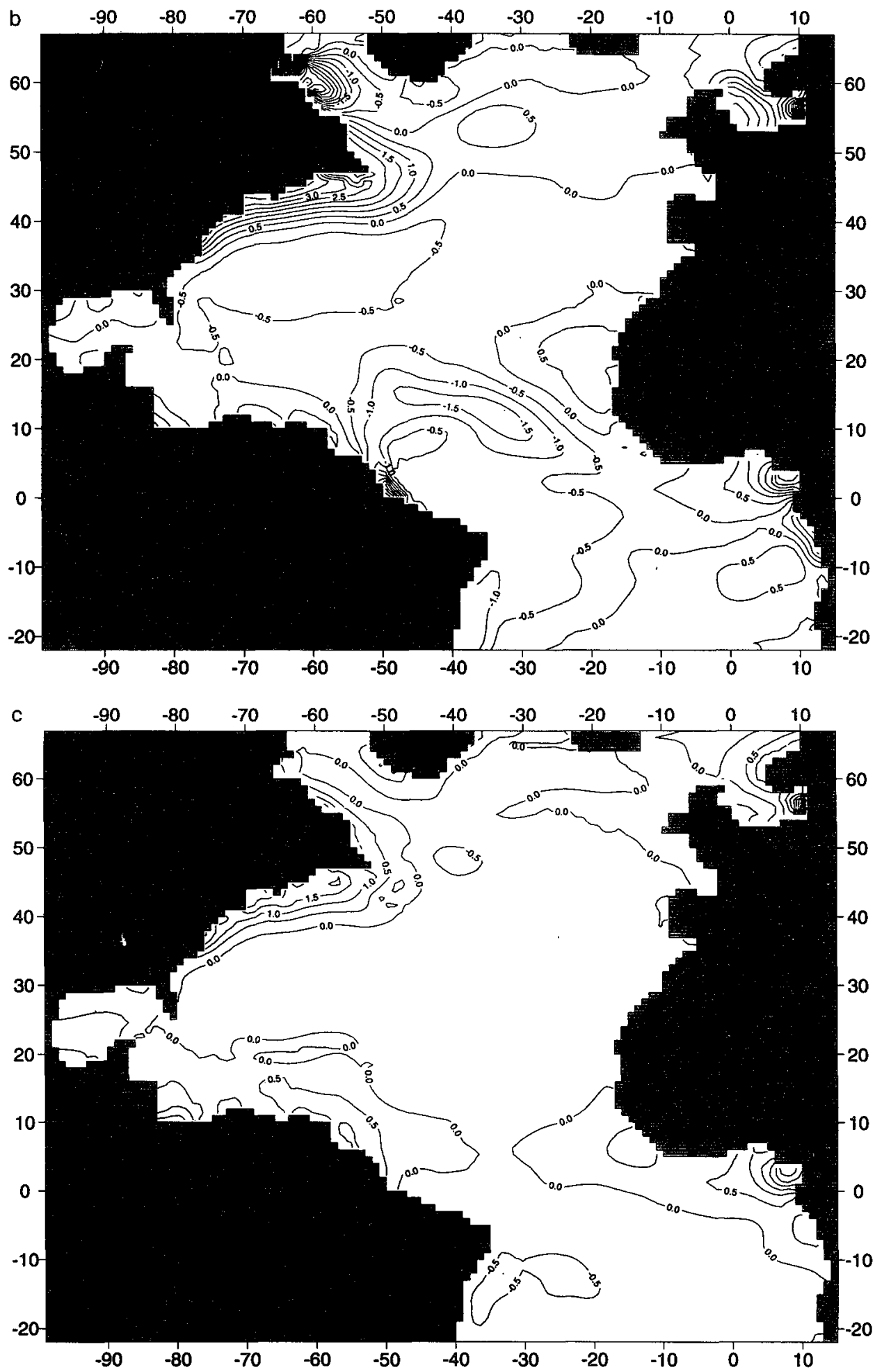

FIG. 3. (Continued) 
TABLE 1. Transports in the model with each surface forcing technique. The Labrador Current transport is that over the shelf of $50^{\circ} \mathrm{N}$, positive northward.

\begin{tabular}{lcccc}
\hline \hline \multicolumn{1}{c}{ Surface forcing } & Labrador Current & Gulf Stream & $\begin{array}{c}\text { Subpolar gyre } \\
\text { (Sv) }\end{array}$ & $\begin{array}{c}\text { Thermohaline } \\
\text { overturning } \\
\text { (Sv) }\end{array}$ \\
\hline End of spinup (3 years) & -0.63 & 43 & 41 & 23 \\
Experiment A surface relaxation (10 years) & -0.21 & 35 & 25 & 18 \\
Experiment B fluxes-virtual salt flux (10 years) & +0.25 & 32 & 26 & 20 \\
Experiment C fluxes-freshwater forcing (10 years) & -0.63 & 43 & 41 & 23 \\
\hline
\end{tabular}

excessively zonal atmospheric model winds in the equatorial band (Slingo et al. 1994). Note that experiment $\mathrm{A}$, in which the surface properties are pushed continually toward the surface climatology, is least in error. Experiment $\mathrm{C}$ shows warmer (and hence better) tropical SST than experiment B. The only difference between the two is in the surface forcing of salinity. The physically correct addition of freshwater in C contrasts with the unphysical extraction of salt in B. Experiment $\mathrm{B}$ has greater upwelling and surface divergence along the equator, which produces cooler temperatures. This is a result of artificial diffusion, subsurface convergence, and increased surface buoyancy. All of these effects are the result of the strongly positive $P-E$ flux near the ITCZ and experiment B's consequent salt sink at the surface. In addition, enhancement of the westward equatorial current, and thus transport of cooler water, is associated with the salt sink of the Amazon and Orinoco in northeast South America.

Apart from these two regions of general model-related error, experiment $\mathrm{C}$ estimates SST within $2^{\circ} \mathrm{C}$ of Levitus (1982) climatology; neither of the other experiments is able to match this. The relaxation experiment, A, consistently overestimates SST throughout the North Atlantic, while experiment B cools the subtropics and warms the northwest Atlantic excessively.

\section{b. Surface salinity}

The difference between Levitus (1982) sea surface salinity (SSS) climatology and the 10-year January SSS for each experiment is shown in Fig. 3. This figure shows much greater contrasts in SSS than does Fig. 1 in SST. The surface relaxation experiment, A, reproduces the SSS well everywhere except in regions of very low salinity near the mouths of large rivers where the additional salt loss due to river input generally results in an underestimate of the salinity by about 1 psu. Experiment B, in contrast, uses the model's diagnosed evaporation and the atmospheric model's precipitation to force the SSS that leads to regions of significant over- and underestimate. Experiment B will partly be in error because the OGCM is being forced by an atmospheric model rather than observed parameters such as rainfall. The distribution, and magnitude, of atmo- spheric model precipitation is one of the poorer modeled atmospheric fields (Gates et al. 1990). However, comparison with experiment $\mathrm{C}$ (Fig. 3c), which has exactly the same $E-P$ flux but a real freshwater, rather than effective salt, flux through the ocean surface, shows that the major errors in experiment B are mostly due to the parameterization of surface forcing. The largest errors in experiment B are off Newfoundland. Section 5 will examine the inaccuracies in this region for each experiment in more detail to quantify the imbalance caused by the effective salt flux.

Experiment C mostly reproduces the SSS to within $0.5 \mathrm{psu}$, as with experiment A, except in four regions. Salinity is overestimated along the west coast of North America, principally because of the model's northward shift in the Gulf Stream [the model's runoff through the St. Lawrence system is $20000 \mathrm{~m}^{3} \mathrm{~s}^{-1}$, comparable to the observed estimate of $15000 \mathrm{~m}^{3} \mathrm{~s}^{-1}$ (Milliman and Meade 1983)]. There is a slight overestimate of SSS in the Amazon plume because of rapid removal of the freshwater in the strong current (Fig. 2) here (recall that this current is too strong due to stronger zonal winds in the atmospheric model than in reality). There are also local overestimates of SSS off the Niger in equatorial Africa and in the Baltic. The latter is poorly resolved at this resolution, while the former (showing a common error in all experiments) is again likely to be due to the overly strong equatorial wind field.

\section{c. Circulation}

A visual comparison of the surface velocities of each experiment reveals relatively small differences between them. However, comparison of integrated quantities shows that this similarity is misleading. Four major circulation indices are shown in Table 1 . The shelf transport of the Labrador Current (the meridional flow at $50^{\circ} \mathrm{N}$, positive northward, across the Grand Banks to $50^{\circ} \mathrm{W}$ ) shows the strength of the coastal current. The Gulf Stream transport is the maximum barotropic flow in the North Atlantic subtropical gyre, as the subpolar gyre transport is for the gyre south of Greenland. The thermohaline overturning transport is the maximum of the zonally average meridional flow in the northern Atlantic.

Assuming the $\mathrm{RD}$ values represent the best this model can do to reproduce reality then experiment $\mathrm{C}$ 
(a) SURFACE RELAXATION

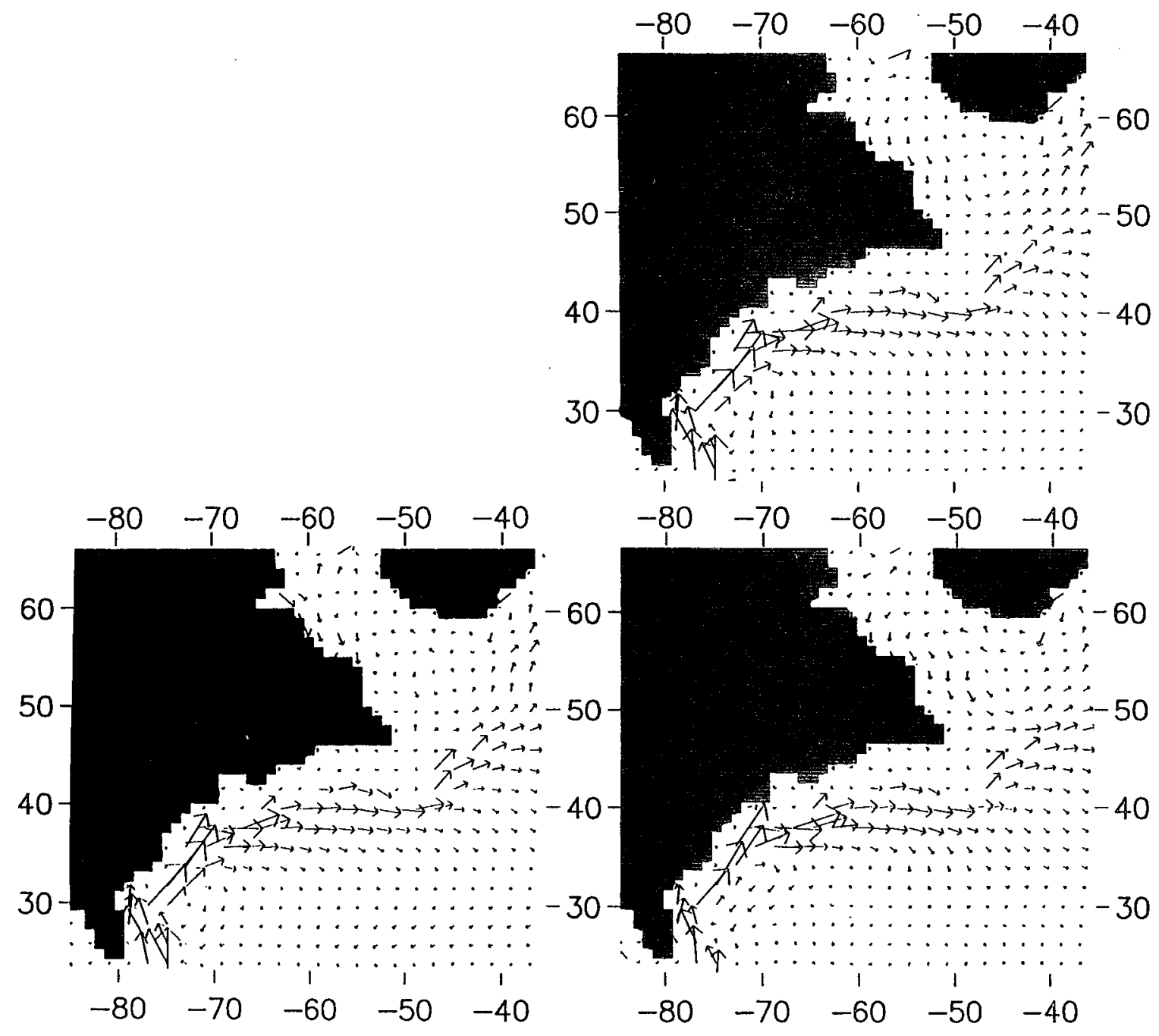

(b) VIRTUAL SALT FLUX

(c) FRESH WATER TRANSPORT

FIG. 4. Surface velocity in January of year 11 in the northwest Atlantic for each of the experiments: (a) experiment A with surface relaxation, (b) experiment B with physically based fluxes (applied as a salt flux), and (c) experiment $C$ with physically based fluxes (applied as a freshwater flux). An arrow length equal to the grid spacing represents a velocity of $10 \mathrm{~cm} \mathrm{~s}^{-1}$.

is clearly extremely successful in all respects, reproducing each of the RD circulation parameters. Experiment $\mathrm{A}$ is able to reproduce a weak southward flowing Labrador shelf current but the flow overturns somewhat weakly. The Labrador current in experiment B does not penetrate as far south as $50^{\circ} \mathrm{N}$, and its overturning strength is only $15 \%$ below the RD mode. Both experiments A and B reproduce similar, weak, gyre strengths.

\section{Detailed examination of the Newfoundland area}

Freshwater flux surface forcing of experiment $\mathrm{C}$ gave a more realistic simulation in all respects than the more conventional virtual salt flux of experiment $B$ and a better circulation (in terms of the parameters in Table 1) than the relaxation experiment $\mathrm{A}$. We have already qualitatively discussed reasons for the poor circulation that might be expected from having a salt flux rather than a freshwater flux at the ocean surface. In this section we will examine the salt fluxes for each experiment in the region of most radical difference between experiments: the Newfoundland area.

First, consider the surface velocity (Fig. 4), SST (Fig. 5), and SSS (Fig. 6) of this region in detail for each experiment. The only significant difference in the surface circulation is the weak subpolar gyre in B, com- 
(a) LEVITUS

\section{(b) SURFACE RELAXATION}
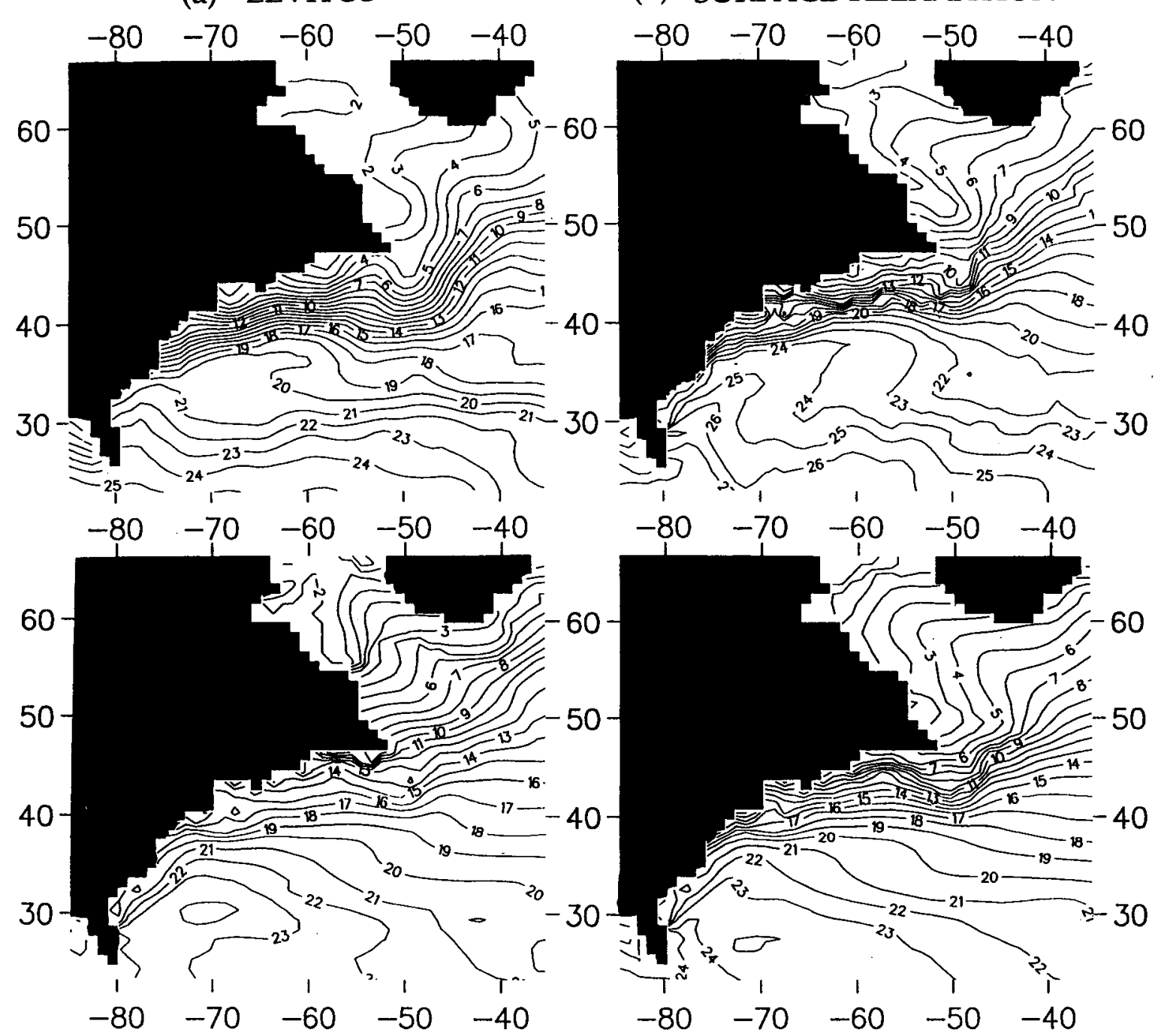

(c) VIRTUAL SALT FLUX

(d) FRESH WATER TRANSPORT

FIG. 5. Surface temperature in January of year 11 in the northwest Atlantic for each of the experiments: (a) Levitus climatology, (b) experiment A with surface relaxation, (c) experiment B with physically based fluxes (applied as a salt flux), and (d) experiment $\mathrm{C}$ with physically based fluxes (applied as a freshwater flux). The contour interval is $1^{\circ} \mathrm{C}$.

pared to A and C; the position and strength of the Gulf Stream is visually identical. The subpolar gyre difference is a surface feature; Table 1 showed that experiment B possessed a comparable subpolar gyre transport to experiment $\mathrm{A}$. Thus, the differences in surface properties shown in Figs. 5 and 6 cannot entirely be due to advection but must also include the influence of diffusion and the local surface/runoff fluxes. Figures 5 and 6 show the excess heat and salt south of Newfoundland in experiment $\mathrm{B}$, compared to experiments $\mathrm{A}$ and C. Note, however, that because of the northward bias of the Gulf Stream all three are warmer and saltier than climatology in this region (see section $4 a$ ). The pene- tration of the $2^{\circ} \mathrm{C}$ contour south of Newfoundland in the climatology (Fig. 5a) suggests that in reality some water passes through the Strait of Belle Isle north of Newfoundland to cool and freshen the waters to the south of the island. This strait is not resolved in our OGCM, which will partly explain the consistent model error in this region. Nevertheless, experiment $C$, unlike either A or B, reproduces a realistic SST east of Newfoundland.

Rather different surface forcing mechanisms occur in each experiment in this region, and these differences are reflected in the shape of the fields in Figs. 5 and 6. In experiment $A$ the surface temperature and salinity 
(a) LEVITUS

\section{(b) SURFACE RELAXATION}
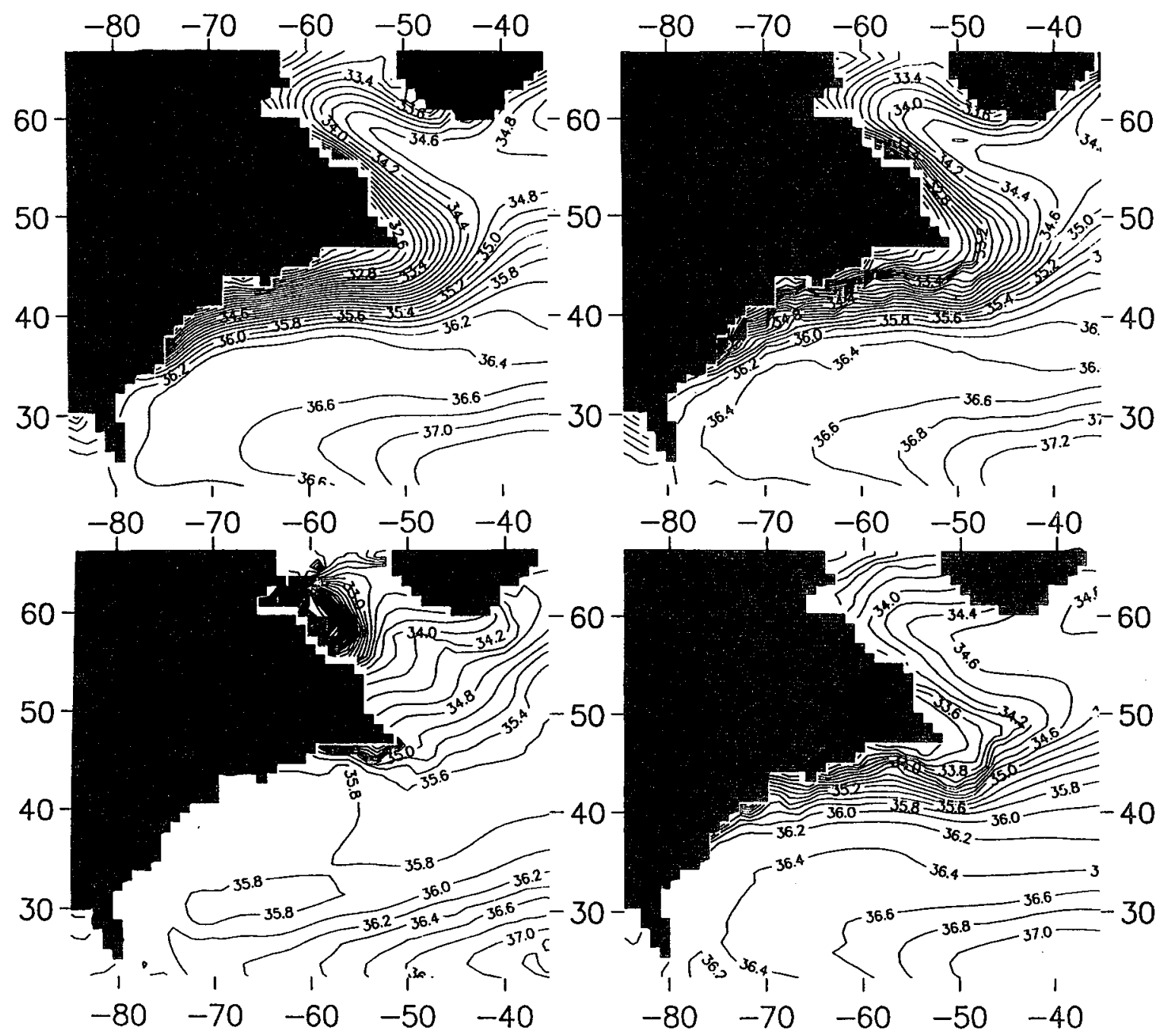

(c) VIRTUAL SALT FLUX

(d) FRESH WATER TRANSPORT

FIG. 6. Surface salinity in January of year 11 in the northwest Atlantic for each of the experiments: (a) Levitus climatology, (b) experiment $A$ with surface relaxation, (c) experiment $B$ with physically based fluxes (applied as a salt flux), and (d) experiment $C$ with physically based fluxes (applied as a freshwater flux). The contour interval is 0.2 psu.

(part b of each figure) are relaxed toward the Levitus climatology (part a of each figure). Thus, the surface fields appear fairly similar to the climatology, with differences being due to inherent inadequacies in internal model dynamics. Some of these basic faults, common to all OGCMs, such as the way surface water penetrates into the interior of the ocean, will have altered the subsurface density structure over the seven years during which the model has run without subsurface relaxation. The surface relaxation will not necessarily, therefore, have retained its original subsurface density field during this period. This enables dynamical differences from the real ocean to arise that push the model deci- sively away from climatology, as is reflected in the surface temperature field between $30^{\circ}$ and $40^{\circ} \mathrm{N}$.

Experiment $\mathrm{B}$ parameterizes surface heat fluxes in a more physically realistic way but has a surface salt source or sink through the $(P-E)$ term. In addition, and most crucially here, there is a strong additional salt sink into the major sources of fresh water in this area: the St. Lawrence $\left(48^{\circ} \mathrm{N}, 57^{\circ} \mathrm{W}\right)$ and Hudson's Bay $\left(60^{\circ} \mathrm{N}, 65^{\circ} \mathrm{W}\right)$. There are removals of salt, in the model, of $\sim 5 \times 10^{5} \mathrm{~kg} \mathrm{~s}^{-1}$ and $1 \times 10^{5} \mathrm{~kg} \mathrm{~s}^{-1}$, respectively, by these freshwater sources. A classical sink shows logarithmic decay behavior in the vicinity of the sink; this is clearly seen in both the temperature (Fig. 5c) and 
salinity (Fig. 6c) fields near these two salt sinks through the rapid decline of the variables over the last few gridpoints.

This behavior contrasts greatly with that in experiment $C$ (Figs. 5d and 6d), where Huang's scheme has enabled both water and salt to be conserved. The freshwater sources, if resolvable, would have a salinity of zero, and a smooth linear mixing would be evident out to the open ocean, in this case a distance of $1000 \mathrm{~km}$ or so. As the model cannot resolve the river/bay inlets, the mixing is instead from a low salinity value for the $25000 \mathrm{~km}^{2}$ of the gridboxes nearest the river to this open ocean regime. This linear decline in salinity in experiment $\mathrm{C}$ highlights the inherent errors introduced by the more conventional artificial salt flux of experiment $B$. The artificial, but pronounced, salt sink off Newfoundland in experiment $B$ has altered the dynamics of the model in this region significantly. The temperature field, which is forced in exactly the same manner in experiments $B$ and $C$, has had to respond in the same sinklike manner in experiment $\mathrm{B}$ as the salt loss drives an artificial flow, at depth, into the shelf region. Similar, but usually weaker, artificial flows will be driven over the whole ocean because $P-E$ is rarely in balance and the conventional artificial salt flux produced by this surface forcing will produce local convergence or divergence.

To summarize, relaxation inevitably maintains a realistic salinity distribution, but the absence of real freshwater fluxes leads to incorrect salt fluxes. A realistic freshwater flux applied as a salt flux also fails to account for the real freshwater flux. Real freshwater forcing includes the effect of advection by the fresh water, giving much more realistic salinities in regions of strong forcing.

\section{Conclusions}

This paper has shown that commonly used surface forcing for salinity produces an artificial salt flux that inevitably leads to long-term drift in the salinity of an OGCM. However, using the freshwater surface flux formulation of Huang (1993), combined with bulk aerodynamical fluxes, removes this problem and produces simulations of circulation and density fields, using as good as those possible via robust diagnostic techniques. In particular, we have illustrated the advantages of this technique in the North Atlantic, showing distinct improvement on effective salt flux model Gulf Stream and tropical circulations.

This contrast between freshwater and effective salt flux forcing has wide implications. Coupled ocean-atmosphere models presently being used for climate prediction typically use an artificial salt flux to determine the salinity. Some of the long-term drift problems of such models may be due to the loss of accuracy in oceanic density fields to which this flux must lead. Feedback processes between an ocean changing den- sity artificially, as salt is lost or gained both regionally and globally, and a model atmosphere will be incorrectly represented. Inaccurate fields of SST so established will lead to poor estimates of surface fluxes to drive the coupled atmospheric model. Implementation of a freshwater flux in oceanic models is therefore vital for realistic climate prediction.

Acknowledgments. This work was supported through NERC Grant GST/02/708. We also thank two anonymous reviewers whose comments led to an improved paper.

\section{REFERENCES}

Atlas of World Water Balance, 1974: Chief Administration of Hydrometeorological Service under the Council of Ministers of the USSR. USSR National Committee of the International Hydrological Decade. The UNESCO Press.

Bigg, G. R., 1994: An ocean general circulation model view of the glacial Mediterranean thermohaline circulation. Paleoceanography, 9, 705-722.

, and D. Jiang, 1993: Modeling the late Quaternary Indian Ocean circulation. Paleoceanography, 8, 23-46.

, - - and J. F. B. Mitchell, 1992: A general circulation model of the Indian Ocean at 9000 years BP. Paleoceanography, 7, 119-135.

Bryan, F., 1986: High-latitude salinity effects and interhemispheric thermohaline circulations. Nature, 323, 301-304.

Bryden, H. L., 1990: Measurement of the flow through the Strait of Gibraltar. Adv. Water Res., 2, 64-69.

Carrington, D. J., and D. L. T. Anderson, 1993: Using an ocean model to validate ECWMF heat fluxes. Quart. J. Roy. Meteor. Soc., 119, 1003-1021.

FRAM Group, 1991: Using an eddy resolving model to study the Southern Ocean. Eos, 72, 15 pp, 169, 174, 175.

Gates, W. L., P. R. Rowntree, and Q.-C. Zeng, 1990: Validation of climate models. Climate Change: The Scientific Assessment, J. T. Houghton, G. J. Jenkins, and J. J. Ephraums, Eds., Cambridge University Press, 93-130.

Han, Y.-J., 1988: Modelling and simulation of the general circulation of the ocean. Physically-Based Modelling and Simulation of Climate and Climatic Change, M. E. Schlesinger, Ed., Kluwer, 465-508.

Haney, R. L., 1974: A numerical study of the response of an idealized ocean to large-scale surface heat and momentum flux. J. Phys. Oceanogr., 4, 145-167.

Hoskins, B. J., and P. J. Valdes, 1990: On the existence of storm tracks. J. Atmos. Sci., 47, 1854-1864.

Huang, R. X., 1993: Real freshwater flux as a natural boundary condition for the salinity balance and thermohaline circulation forced by evaporation and precipitation. J. Phys. Oceanogr., 23, $2428-2446$.

Lazier, J. R. N., and D. G. Wright, 1993: Annual velocity variations in the Labrador Current. J. Phys. Oceanogr., 23, 659-678.

Levitus, S., 1982: Climatological Atlas of the World Ocean. NOAA Prof. Paper No. 13, U.S. Dept. of Commerce, 173 pp.

, and A. Oort, 1977: Global analysis of oceanographic data. Bull. Amer. Meteor. Soc., 58, 1270-1284.

McCreary, J. P., and P. K. Kundu, 1989: A numerical investigation of sea surface temperature variability in the Arabian Sea. $J$. Geophys. Res., 94, $16097-16114$.

Milliman, J. D., and R. H. Meade, 1983: World-wide delivery of river sediment to the occans. J. Geol., 91 (1), 1-21.

Moore, A. M., and C. J. C. Reason, 1993: The response of a global ocean general circulation model to climatological surface boundary conditions for temperature and salinity. J. Phys. Oceanogr., 23, 300-328. 
Philander, S. G. H., and A. D. Seigel, 1985: Simulation of El Niño of 1982-1983. Coupled Ocean-Atmosphere Models, J. C. J. Nihoul, Ed., Elsevier, 517-542.

Power, S. B., A. M. Moore, D. A. Post, N. R. Smith, and R. Kleeman, 1994: Stability of North Atlantic Deep Water formation in a global ocean general circulation model. J. Phys. Oceanogr., 24, 904-916.

Saltzman, B., and R. E. Moritz, 1980; A time-dependent climatic feedback system involving sea-ice extent, ocean temperature, and $\mathrm{CO}_{2}$. Tellus, 32, 93-118.

Sarmiento, J. L., and K. Bryan, 1982: An ocean transport model for the North Atlantic. J. Geophys. Res., 87, 394-408.

Semtner, A. J., and R. M. Chervin, 1988: A simulation of the global ocean circulation with resolved eddies. J. Geophys. Res., 93(C12), $15502-15522$ and $15767-15775$.

- , and -1992 : Ocean General Circulation from a global eddy-resolving model. J. Geophys. Res., 97(C4), 5493-5550.
Slingo, J., M. Blackburn, A. Betts, R. Brugge, K. Hodges, B. Hoskins, M. Miller, L. Steenmanclark, and J. Thuburn, 1994: Mean climate and transience in the tropics of the UGAMP GCM - sensitivity to convective parameterisation. Quart. J. Roy. Meteor. Soc., 120, 881-922.

Stevens, D. P., 1990: On open boundary conditions for three dimensional primitive equation ocean circulation models. Geophys. Astrophys. Fluid Dyn., 51, 103-133.

- 1991: A numerical ocean circulation model of the Norwegian and Greenland Seas. Progress in Oceanography, Vol. 27, Pergamon, 365-402.

Weaver, A. J., and E. S. Sarachik, 1991: The role of mixed boundary conditions in numerical models of the oceans climate. J. Phys. Oceanogr., 21, 1470-1493.

Welander, P., and J. Willebrand, 1988: Instability and multiple steady states in a meridional-plane model of the thermohaline circulation. Tellus, 40A, 162-172. 